\title{
VIOLÊNCIAS E DILEMAS DO CONTROLE SOCIAL NAS SOCIEDADES DA "MODERNIDADE TARDIA"
}

\author{
José Vicente Tavares dos Santos
}

\begin{abstract}
Resumo: O objetivo deste artigo é analisar os fenômenos da violência difusa na sociedade contemporânea e discutir os dilemas do controle social. A emergência de uma noção de segurança cidadã, na perspectiva da mundialização, supõe a construção social de novas modalidades de controle social orientadas pelo respeito à dignidade humana.

Palavras-chave: controle social; conflitualidades; segurança cidadã.
\end{abstract}

Abstract: The objective of this article is to analyze the phenomenon of diffuse violence in society and to discuss the dilemmas of social control. The emergence of the notion of citizen safety, as seen from the perspective of globalization, presupposes the construction of new modes of social control based on respect for human dignity.

Key words: social control; conflict; citizen safety.

$\mathrm{O}$ objetivo deste artigo é analisar os fenômenos da violência difusa na sociedade contemporânea e discutir os dilemas do controle social, informal e formal. Estudaremos as modificações na construção de objetos sociais, expressos como problemas sociais, construídos por atores, instituições e discursos: "conflitualidade", "violência", "criminalização", "controle social", "tecnologias sociais de poder", "conflitos sociais" e "lutas sociais contra a violência". O alvo teórico é continuar o desenvolvimento de uma Sociologia da Conflitualidade, abordagem sociológica que pretende explicar os processos de conflitualidade social, contraditórios e conflitivos, salientando a necessidade da discussão política sobre o controle social.

Quais as possibilidades de ser instituída uma concepção de segurança cidadã, ou seja, um modelo de controle social que incorpore a participação social de modo a revitalizar os espaços urbanos, cêntricos e periféricos, garantindo uma vida cotidiana saudável?

$\mathrm{O}$ fenômeno da violência difusa consiste em um processo social diverso do crime, anterior ao crime ou ainda não codificado como crime no Código Penal. Durkheim considera o crime um fenômeno social normal, pois, em toda sociedade, um certo número de crimes é cometido e, por conseqüência, se nos referimos ao que se passa regularmente, o crime não é um fenômeno patológico. Igualmente, uma certa taxa de suicídios pode ser considerada normal (Aron, 1967:340). Ainda assim, o crime é considerado por Durhkeim uma ruptura com a consciência coletiva, razão pela qual sofre punição pela lei penal. Ao contrário, afigura-se que a violência difusa nas sociedades do século XXI é, em larga medida, legitimada pela consciência coletiva, instituindo-se como norma social, ainda que controversa e polêmica.

Entre os conflitos sociais atuais, crescem os fenômenos da violência difusa e as dificuldades das sociedades e dos Estados contemporâneos em enfrentá-los (Giddens, 1966). Tal dificuldade expressa os novos limites da formação política da "modernidade tardia", pois os laços de interação social são orientados por modos violentos de sociabilidade, invertendo as expectativas do processo civilizatório (Harvey, 1993:17). Afirma Sousa Santos (1994:271): “(...) o Estado perde o monopólio da violência legítima que durante dois séculos foi considerada a sua característica mais distintiva. (...) Em geral os Estados periféricos nunca atingiram na prática o 
monopólio da violência, mas parecem estar hoje mais longe de o conseguirem do que nunca". As raízes sociais desses atos de violência difusa parecem localizar-se nos processos de fragmentação social, os quais refletem "a desagregação dos princípios organizadores da solidariedade e a crise da concepção tradicional dos direitos sociais em oferecer um quadro para pensar os excluídos". (Rosanvallon, 1995:9). Em outras palavras, estamos diante de processos de massificação paralelos a processos de individualização - "Somos células em uma sociedade de massas. A globalização é celular", pois a "multidão solitária" vive em uma pluralidade de códigos de conduta (Díaz, 1989:89-91). A cultura pós-moderna privilegia o acontecimento: "A realidade pós-moderna assume a existência de conflitos irresolúveis” (Díaz, 1989:37). Desenvolve-se a vivência de uma incerteza: "O mundo pós-moderno está se preparando para a vida sob uma condição de incerteza que é permanente e irredutível" (Bauman, 1998:32).

Esta é uma das facetas da lógica cultural do capitalismo avançado: a pluralidade, a descontinuidade, a dispersão (Jameson,1996). Como evoca Díaz (1989:17): "Nossa época, desencantada, se desembaraça das utopias, reafirma o presente, resgata fragmentos do passado e não possui demasiadas ilusões a respeito do futuro". As relações de sociabilidade passam por uma nova mutação, mediante processos simultâneos de integração comunitária e de fragmentação social, de massificação e de individualização, de ocidentalização e de desterritorialização (Ianni, 1996). Repõe-se o problema de qual é o lugar da alteridade cultural na sociedade em processo de mundialização: "Nas sociedades do capitalismo tardio, o culto da liberdade individual e o desdobramento da personalidade se reformam e se localizam no centro mesmo das preocupações" (Díaz, 1989:17). Retoma-se uma inquietação que estava presente nos primeiros sociólogos, pois: "O projeto sociológico nasceu de uma inquietude sobre a capacidade de integração nas sociedades modernas: como estabelecer ou restaurar os laços sociais em sociedades fundadas na soberania do indivíduo?" (Schnapper, 1998: 15). Rompe-se a consciência coletiva da integração social, um "declínio dos valores coletivos e com o crescimento de uma sociedade extremamente individualista" (Hobsbawm, 2000:136).

As questões sociais, desde o século XIX centradas em torno do trabalho (Castel, 1998), tornam-se questões complexas e mundiais, pois várias são as dimensões do social que passam a ser questionadas, entre elas a questão dos vínculos sociais. Trata-se de uma ruptura do contrato social e dos laços sociais, provocando fenômenos de “desfiliação" e de ruptura nas relações de alteridade, dilacerando o vínculo entre o eu e o outro.

No limiar do século XXI, o panorama mundial é marcado por questões sociais mundiais que se manifestam, de forma articulada e com distintas especificidades, nas diferentes sociedades. Paradoxalmente, o internacionalismo está fundado em problemas sociais globais, tais como a violência, a exclusão, as discriminações por gênero, os vários racismos, a pobreza, os problemas do meio ambiente e a questão da fome. As transformações do mundo do trabalho, mediante as mudanças tecnológicas, com novas possibilidades de emprego em determinados setores as quais vêm acompanhadas pela precarização do trabalho, pelo desemprego e pelo processo de seleção/exclusão social (Larangeira, 1999). Instaura-se um modo de organização da produção pós-fordista, caracterizado pela desregulamentação, pela crise do salariado: a precarização do assalariamento como princípio da conflitualidade social, redução do mercado de emprego formal, provocando a "desfiliação" dos trabalhadores em relação às estruturas coletivas do mundo do trabalho (Castel, 1998; Taylor, 1999:224; Garland, 2001:81-82).

Conforme situa Hespanha (1999): "E não só as velhas desigualdades baseadas nas diferenças de classes e de estatuto social em termos de rendimento, capital educacional ou prestígio não desapareceram como emergiram (ou tornaram-se mais visíveis) novas desigualdades baseadas em outros fatores de distinção como o sexo, a etnia, a religião ou os modos de vida" (Hespanha, 1999:70). Neste contexto, emergem diferentes formas de desigualdade e de subordinação, seja em trabalhos temporários, seja pelo surgimento dos "novos pobres" ou pela vivência da "miséria do mundo" (Taylor, 1999:12; Bourdieu, 1993).

Também são relevantes as mudanças no mundo rural, desde a questão global da fome até as inovações tecnológicas, e as novas formas de organização produtiva, como a agricultura familiar e as atuais lutas sociais pela terra em diferentes países. A importância para o futuro da relação do homem com a natureza, indicando a questão ecológica, a discussão sobre as tecnologias intermediárias e a noção de desenvolvimento com sustentabilidade (Sachs, 1993). Desencadeiam-se processo de exclusão social: os "sem classe", "sem terra", aqueles que vivem a exclusão digital, os "sem teto", aqueles que passam fome ou os "sem trabalho". 
Um novo espaço social mundial de conflitualidades está se desenhando nos espaços e nos tempos da globalização (Ianni, 1996; Sousa Santos, 1994; Harvey, 1993; Giddens, 1991), com a predominância da mercantilização do social e a destruição das sociabilidades coletivas, ou seja, "o mercado é agora a fundamental força motor das práticas e discursos sociais e políticos contemporâneos", com o "desenvolvimento de novas formas de desigualdade social (Taylor, 1999:54).

As instituições socializadoras vivem um processo de crise e desinstitucionalização, a família, escola, processos de socialização, fábricas, religiões, e o sistema de justiça criminal (polícias, tribunais, manicômios judiciários, prisões).

A crise da família avoluma-se, seja pela desnaturação da ordem patriarcal realizada pelo movimento feminista, a crítica da dominação masculina (Bourdieu, 1998), seja pelo registro da violência doméstica (Saffioti; Almeida, 1995; Gregori, 1992). Analisa Garland (2001:82-83): “A estrutura da família foi substancialmente transformada. Houve um acentuado declínio (e concentração no tempo) da fertilidade, com as mulheres se casando mais tarde, tendo poucos filhos e reentrando no trabalho remunerado imediatamente após dar a luz. Houve também um súbito e notável aumento dos divórcios". Também as dificuldades da identidade de gênero (Taylor, 1999:37-41) e as transformações da posição das mulheres na sociedade contemporânea.

A crise da família cristaliza tais mudanças nos laços sociais, pois as funções sociais desta unidade social marcada por relações de parentesco - assegurar a reprodução da espécie, realizar a socialização dos filhos, garantir a reprodução do capital econômico e da propriedade do grupo, assegurar a transmissão e reprodução do capital cultural - estão atualmente ameaçadas.

Por um lado, em decorrência da própria diversidade de tipos de família no Brasil atual - família nuclear, família extensa em algumas áreas rurais, famílias monoparentais, famílias por agregação. Por outro, os tipos de relações de sociabilidade que nela se realizam são variadas, marcadas originalmente pela afetividade e pela solidariedade, agora reaparecem como largamente conflitivas, como o demonstram os fenômenos da violência doméstica. Finalmente, as funções de socialização são compartilhadas pela escola e pelos meios de comunicação. Dessa forma, identifica-se uma desorganização do grupo familiar, com as funções de reprodução econômica ameaçadas pela crise do emprego assim como pelos efeitos da crise do Estado-Providência.

\section{A VIOLÊNCIA DIFUSA NA "MODERNIDADE TARDIA"}

Os fenômenos da violência difusa adquirem novos contornos, passando a disseminar-se por toda a sociedade. Essa multiplicidade das formas de violência presentes nas sociedades contemporâneas - violência ecológica, exclusão social, violência entre os gêneros, racismos, violência na escola - configuram-se como um processo de dilaceramento da cidadania. A compreensão da fenomenologia da violência pode ser realizada a partir da noção de uma microfísica do poder, de Foucault, ou seja, de uma rede de poderes que permeia todas as relações sociais, marcando as interações entre os grupos e as classes (Foucault, 1994:38-39). Deparamo-nos com as dimensões subjetivas e objetivas das variadas formas de violências: violência na escola, violência social, ecológica, exclusão, gênero, racismos. Configura-se uma "microfísica da violência" na vida cotidiana da sociedade contemporânea (Tavares dos Santos, 2002b).

Efetiva-se uma pluralidade de diferentes tipos de normas sociais, algo mais do que o próprio pluralismo jurídico, levando-nos a ver a simultaneidade de padrões de orientação da conduta muitas vezes divergentes e incompatíveis, como, por exemplo, a violência configurando-se como linguagem e como norma social para algumas categorias sociais, em contraponto àquelas denominadas de normas civilizadas, marcadas pelo autocontrole e pelo controle social institucionalizado (Elias, 1990; 1993). Fortalece-se a prática de fazer justiça pelas próprias mãos, um traço de uma cultura orientada pelo hiperindividualismo (Díaz, 1898, 107). Nas palavras de Bauman (1998:26): “A busca da pureza moderna expressou-se diariamente com a ação punitiva contra as classes perigosas; a busca da pureza pós-moderna expressa-se diariamente com a ação punitiva contra os moradores das ruas pobres e das áreas urbanas proibidas, os vagabundos e os indolentes". Adquirindo a cultura uma centralidade na "modernidade tardia", a disseminação de uma cultura de "ganhadores ou perdedores" (Taylor, 1999: 34-37) acentua os valores do individualismo competitivo e a criação de uma cultura popular unidimensional, hedonista e imediatista (Young, 1999:10; Taylor, 1999:90), induz as populações a viverem em novos grupos sociais eletivos e auto-referidos (Garland, 2001:89).

O período atual pode ser denominado de Processo de Mundialização, marcado pela pós-modernidade como forma cultural, pela expansão da produção industrial em 
nova distribuição do trabalho planetária, com o avanço do capital especulativo e pelas conflitualidades sociais mundiais.

A herança do Estado de Bem-Estar Social e do Modernismo Penal (1946-1978) começou a ser abalada durante a crise global do final do século XX (1978-1991), como comprova Hobsbawm (1994; 2000): assistimos ao final do "Estado de Bem-Estar" (1946-1973), no qual as instituições sociais tinham um funcionamento regular, ao menos nos países desenvolvidos. O controle social formal (as polícias, o judiciário, o sistema da justiça criminal, as prisões) era orientado para a reabilitação dos delinqüentes, com uma intenção "correcional" e ressocializadora. Porém, também nessa época as instituições de controle social informal funcionavam regularmente: a família, a escola, os grupos sociais, as associações, os movimentos sociais definiam normas de conduta, reproduziam valores e disseminavam orientações para a ação social. Estávamos vivendo o modelo de controle social "correcional", pois todos os controles sociais, informais e formais, estavam em funcionamento, conforme a interpretação de Garland (2001:44): "O bem-estar penal retirava suporte de uma particular forma de Estado e de uma particular estrutura de relações de classes. Funcionava em um ambiente específico de políticas sociais e econômicas e interagia com uma série de instituições contíguas, as mais importantes das quais eram o mercado de trabalho e as instituições do Estado de Bem-estar Social". Por outro lado, o controle social distribuía-se pelas instituições societárias: "Os controles sociais informais exercidos pelas famílias, vizinhanças e comunidades, junto com as disciplinas impostas pelas escolas, locais de trabalho e outras instituições criavam um cotidiano de normas e sanções que embasavam as demandas legais e garantiam suporte às intervenções do bem-estar penal" (Garland, 2001:44). Uma das novas questões sociais mundiais tem sido a violência no espaço escolar, marcada pela violência simbólica e pela territorialização do crime organizado (Tavares dos Santos, 1999), também um sintoma da crise da juventude masculina (Taylor, 1999:65-85; Zaluar, 1994).

O crime seria um epifenômeno da sociedade capitalista, diziam em 1973 os autores da New Criminology, denominados, ao longo dos anos 90, de "realistas de esquerda" na Inglaterra (Taylor; Walton; Young; 1990). Entretanto, acompanhando as mudanças sociais no final do século XX, três décadas depois os "realistas de esquerda" chegariam a perceber os dilemas da "modernidade tardia": as crescentes taxas de criminalidade; a revelação das invisíveis vítimas; a problematização do fenômeno criminal; a universalidade do crime; e a seletividade da justiça; os problemas da punição e da culpabilidade (Young, 1999: 35-43).

As características da "modernidade tardia" seriam a repetição da exclusão social, a disseminação das violências, a ruptura de laços sociais e a "desfiliação" de algumas categorias sociais, como a juventude, uma das grandes vítimas da civilização, analisa Pais: "Nas décadas imediatas ao pós-guerra, as transições dos jovens assemelhavam-se a viagens de comboios nas quais os jovens, dependendo da sua classe social, gênero e qualificações acadêmicas, embarcavam em diferentes comboios com destinos pré-determinados". Atualmente, "o terreno onde as transições têm lugar é de natureza cada vez mais labiríntica. No labirinto da vida, como num labirinto rodoviário, surgem freqüentemente sentidos obrigatórios e proibidos, alterações de trânsito, caminhos que parecem já ter sido cruzados, várias vezes passados: essa retomada de caminhos que parecem que provoca uma sensação de perda, de confusão" (Pais, 2001:10).

Houve profundas alterações no espaço urbano, modificando a visão da ecologia urbana da Escola de Chicago, pois a hegemonia "da sociedade de mercado" envolve um crítico processo de retirada da autoridade pública da supervisão e manutenção dos espaços públicos na cidade" (Taylor, 1999:61). Completa Garland: "Os projetos de renovação urbana dos anos de 1960 continuaram o processo demolindo muitas vizinhanças das áreas urbanas centrais, o que resultou em novos sistemas de tráfico e auto-estradas, com a realocação dos moradores em projetos habitacionais concentrados. O efeito freqüentemente foi concentrar as famílias pobres e de minorias em áreas muito afastadas da cidade nas quais faltavam os serviços básicos tais como lojas, empregos e bom transporte público" (Garland, 2001:84-85).

Produziu-se uma urbanização sociopática, com espaços urbanos fragmentados e segmentados, seguindo um mesmo padrão geral: centros deteriorados e bairros periféricos carentes, habitados por populações vulneráveis; bairros de populações de altas rendas, com forte presença de segurança privada assim como a implementação de condomínios fechados (Caldeira, 2000); territórios controlados pelo "crime organizado"; espaços privados de comércio, com controle social por segurança privada; desigualdade social e espacial; violência cotidiana nas ruas; e violência no espaço escolar (Taylor, 1999:110). Em suma, a falência do poder público regulatório. 
Vivemos em um contexto societário no qual as concepções do crime passam por grandes metamorfoses (Young, 1999:46-47): a definição do crime passa a ser problemática, seja pelas novas modalidades de crime criminalidade violenta; crime organizado, tráfico de armas e de drogas; crimes de "colarinho branco", crimes informacionais, seja por fenômenos sociais de violência contra a pessoa ainda não consideradas, por exemplo, as violências contra as crianças, sob a ideologia da educação pelo castigo físico; os infratores da lei não são mais uma minoria mas podem ser extensos continentes sociais; a probabilidade de alguém ser vítima, de excepcional, passa a ser prevalecente e contingente; as causas do crime são difusas, eminentes ou por "escolha racional", nos casos de delitos contra o patrimônio ou de extorsão por seqüestro; há uma continuidade entre o fato social normal e o crime, transformado em fenômenos societários; o assaltante deixa de ser profissionalizado para tornar-se um ofensor sem especialização, realizando a ação delituosa quase ao acaso (Pegoraro, 1999); a relação entre agressores e vítimas passa a ser uma relação complexa, pois o agressor não é mais somente o estranho, mas alguém conhecido ou do próprio grupo da vítima, estranhos e íntimos, habitantes locais e de outras regiões; as causas do crime passam a ser multidimensionais; o crime passa a ser societal, em um continuum na vida social, sendo o lugar da ocorrência ser tanto privado quanto público; e o controle social formal não mais é monopólio do sistema de justiça criminal mas passa a ser compartilhado por outras agências sociais.

Por conseguinte, os "impactos da modernidade tardia sobre as taxas de crime foram multidimensionais: aumento das oportunidades para o crime; redução dos controles situacionais; aumento da população em risco; redução da eficácia dos auto-controles sociais como conseqüência das mudanças na ecologia social e nas normas culturais" (Garland, 2001:90).

Estaríamos diante de uma crise da modernidade tardia, na qual a privação relativa combina-se com o individualismo, transformando-se em "uma comparação no interior da divisão do trabalho e entre aqueles que estão no mercado e os excluídos, conformando uma grande vulnerabilidade social, pobreza e miséria. Assiste-se, nesse quadro, a uma ruptura dos controles sociais tradicionais (Young, 1999:46-48), substituídos por uma invasão dos meios de comunicação na esfera da socialização. Cabe falar, então, de um tempo histórico não linear, pontual, repetitivo, de uma sociedade de risco (Young, 1999:68-72), na qual a falência do controle social formal se expressa na crise mundial das polícias (Reiner, 2000; Bayley, 1996; Soares, 2000).

\section{AS CONFLITUALIDADES SOCIAIS NO PROCESSO DE MUNDIALIZAÇÃO}

No início do século XXI, a questão das conflitualidades - das formas de violência, das metamorfoses do crime, da crise das instituições de controle social e dos conflitos sociais - configura-se pela emergência de novas modalidades de ação coletiva, com lutas sociais protagonizadas por outros agentes sociais e diferentes pautas de reivindicações.

As questões substantivas - emergentes de pesquisas tanto no espaço urbano quanto no espaço rural - para o futuro da transformação social das sociedades latino-americanas, podem ser assim formuladas (Tavares dos Santos, 2002c): "Quais as formas de violências que predominam na América Latina no início do século XXI? Quais as origens sociais, econômicas e políticas das violências? Qual a relação entre juventude e violência? Como se conforma a crise do sistema de Justiça Penal? Quais as experiências inovadoras e as lutas sociais pela cidadania que se configuram atualmente na América Latina?"

A observação de um fato social - as violências disseminadas pelo espaço social - possibilita a construção de um objeto sociológico, mediante a ótica espaço-temporal da conflitualidade, tecendo uma explicação sociológica da violência, a partir da experiência latino-americana, mas com alcance teórico para várias sociedades contemporâneas, pois nos encontramos diante da mundialização da violência e da injustiça (Tavares dos Santos, 2002a).

$\mathrm{Na}$ sociedade brasileira, a Constituição de 1988, denominada de Constituição Cidadã, representou a instauração do Estado Democrático de Direito, com inúmeras possibilidades de aumento no acesso à Justiça, abrindo um processo de informalização da Justiça (Azevedo, 2000). Entretanto, foi escassa a discussão sobre o direito à segurança, prevalecendo o ponto de vista dos comandos das Polícias Militares estaduais, o qual garantiu a definição constitucional dessas polícias como força auxiliar das forças armadas (Constituição Federal de 1988, art. 144) (Caldeira, 2000).

As forças sociais democráticas vinham fazendo a denúncia de graves violações de direitos humanos desde os anos de "chumbo" da ditadura militar. Por um lado, os liberais consideravam que o Estado de Direito superaria 
tanto a violência do Estado quanto a criminalidade. Por outro, as forças de esquerda falavam em violência estrutural do modo de produção capitalista, considerando o crime um epifenômeno das relações de exploração. Poucos percebiam as relações entre cultura e violência como estratégia de sobrevivência para algumas camadas populares (Oliven, 1982).

Somente nos anos 90, a violência veio a tornar-se um problema social e uma questão sociológica. Os estudos sobre o crime já estavam presentes na historiografia brasileira (Bretas, 1991), os processos da violência política rural já vinham sendo analisados, com larga tradição nos estudos sociológicos (Tavares dos Santos, 1991), e a denúncia da violência contra os trabalhadores rurais e camponeses passou a ser sistemática (CPT, 1989a-2002). A noção de "criminalidade violenta" passou a ser um instrumento chave para explicar a junção do crime com a violência, inaugurando uma larga série de pesquisas e estudos de caso (Adorno, 1993; Zaluar, 1999; Kant de Lima et al., 2002). Em outras palavras, a publicação de uma série de resenhas sobre o estado da arte dos estudos sociológicos sobre crime e violência, incluindo os estudos sobre as polícias, a segurança pública, o poder judiciário penal, as prisões e os fenômenos de violência na escola (Sposito, 2001). A diversidade regional dos estudos já possibilita também uma visão comparativa entre cidades e Estados, acrescendo a visibilidade social e a compreensão sociológica das conflitualidades na sociedade brasileira.

No início do século XXI, a questão das conflitualidades - das formas de violência, das metamorfoses do crime, da crise das instituições de controle social e dos conflitos sociais - configura-se pela emergência de novas modalidades de conflitos sociais: "Estamos em presença de um social heterogêneo, no qual nem indivíduos nem grupos parecem reconhecer valores coletivos. Esse contexto dá origem a múltiplos arranjos societários, a múltiplas lógicas de condutas. Predominando tal situação é válido falar em sociedade fragmentada, plural, diferenciada, heterogênea" (Grossi Porto, 1994). Conformam-se novas questões sociais mundiais, seja porque "os processos de transformação pelas quais vem passando o trabalho afetam sua característica de integração social, com uma configuração fundamentalmente marcada pela fragmentação" (Grossi Porto, 1994), seja pela expansão dos fenômenos da violência difusa, para cuja explicação poderia ser útil uma microfísica da violência (Tavares dos Santos, 2002). Retomamos esta definição de violência difusa: as diferentes formas de violência presentes em cada um dos conjuntos relacionais que estruturam o social podem ser explicadas se compreendermos a violência como um ato de excesso, qualitativamente distinto, que se verifica no exercício de cada relação de poder presente nas relações sociais de produção do social. A idéia de força, ou de coerção, supõe um dano que se produz em outro indivíduo ou grupo social, seja pertencente a uma classe ou categoria social, a um gênero ou a uma etnia, a um grupo etário ou cultural. Força, coerção e dano, em relação ao outro, enquanto um ato de excesso presente nas relações de poder. Podese verificar empiricamente na sociedade brasileira a seletividade social das vítimas: trabalhadores urbanos, moradores de bairros populares, pais, crianças, mulheres, jovens, negros, índios. Do sexo masculino: acidentes de trânsito, homicídios, armas de fogo; jovens e adolescentes: abuso sexual; violência doméstica (contra crianças, idosos, mulheres): contra crianças, castigos corporais e maus-tratos; violência sexual contra as mulheres e o aumento do registro da violência doméstica.

\section{A PRODUÇÃO DO ESTADO DE CONTROLE SOCIAL PENAL}

A violência como nova questão social global está provocando mudanças nos diferentes Estados, com a configuração de Estado de Controle Social repressivo: em outras palavras, estamos diante de formas contemporâneas de controle social, com as características de um Estado repressivo acompanhando a crise do Estado-Providência. Alguns elementos possibilitam caracterizar este estado penal:

- O discricionarismo e a violência policial aparecem como umas das novas questões sociais globais, em grande parte ainda impensada pela sociologia, na perspectiva da conflitualidade. Na última década, a questão policial tornou-se mais complexa, seja pela suposta ineficácia e ineficiência frente ao crescimento e diferenciação das ações sociais socialmente criminalizadas, seja pelos novos fenômenos criminalizados na "modernidade tardia" nos países centrais do mundo capitalista (Young, 1999). Expande-se, pelo planeta, a opção pelo crescimento das funções de controle social repressivo da polícia, com o apelo sistemático ao uso da violência ilegal e ilegítima.

- A produção social do sentimento de insegurança: “Os homens e as mulheres pós-modernos trocaram um quinhão de suas possibilidades de segurança por um quinhão de felicidade. Os mal-estares da modernidade provinham de 
uma espécie de segurança que tolerava uma liberdade pequena demais na busca da felicidade individual. Os malestares da pós-modernidade provêm de uma espécie de liberdade de procura do prazer que tolera uma segurança individual pequena demais" (Bauman, 1998:10). Tal incerteza tem sido produzida pelo enfraquecimento dos laços sociais, desde a insegurança no emprego à crise das relações sociais entre as pessoas (Hobsbawm, 2000:138194; Bauman, 1998:32-35; Garland, 2001:92). A reação do público seria marcada pelo "medo do crime" e pelo "pânico moral", a "sensação de insegurança" (Young, 1999), o "medo de falhar" similar ao "medo do outro", uma crise da civilidade na vida cotidiana (Taylor, 1999:1719).

- O programa de "tolerância zero", da polícia de Nova York, somente em seu aspecto de reforço do policiamento ostensivo mas desprezando toda a rede de serviços de associações que, naquela cidade, faz parte do programa (Young, 1999:121-148).

- O controle social do crime não é mais apenas das agências estatais, mas também das polícias privadas, formais ou precárias, configurando um "complexo de serviços privados de segurança".

- O encarceramento dos "consumidores falhos", pois "a busca da pureza pós-moderna expressa-se diariamente com a ação punitiva contra os moradores das ruas pobres e das áreas urbanas proibidas, os vagabundos e os indolentes" (Bauman, 1998:26). Consolidou-se a indústria carcerária: "Durante os últimos vinte e cinco anos, a população de encarcerados e de todos os que obtêm a sua subsistência da indústria carcerária - a polícia, os advogados, os fornecedores de equipamento carcerário - tem crescido constantemente. O mesmo aconteceu com a população de ociosos - exonerados, abandonados, excluídos da vida econômica e social. Conseqüentemente, como seria previsível, aumentou o sentimento popular de insegurança" (Bauman, 1998:49; Wacquant, 2000). Finalmente, a barbárie das prisões enquanto depósito de "hombres infames", nas quais passa a predominar uma orientação repressiva, aumenta a duração das penas privativas de liberdade, restringindo-se a vida dos apenados nos presídios de segurança máxima, com o abandono dos ideais "correcionais" da época anterior.

Em síntese, o Estado do controle social penal apresenta as seguintes características: a polícia repressiva, o Judiciário penalizante, a privatização do controle social, fazendo com que o crescimento das polícias privadas e das prisões privadas seja acompanhado pelo "complexo industrial-policial", ou todos os ramos industriais envolvidos com equipamentos e instalações de prevenção e repressão ao crime, tais como seguros, segurança privada, viaturas, equipamentos de comunicação, sistemas de informação, etc. (Taylor, 1999:213-222).

As dificuldades políticas advindas dos processos de transição democrática na América Latina, nos últimos 20 anos, pois não só permanece o desconhecimento e a surpresa, em face da expansão dos fenômenos de violência, como nos esforços de reconstrução institucional visando a plenitude do Estado de Direito não foi colocada em questão várias dimensões do controle social institucional, em particular, a situação das prisões e os modos de funcionamento das polícias. Cabe salientar as dificuldades de acesso à justiça, a seletividade social da justiça penal e a perda de legitimidade das instituições de controle social.

As lutas sociais contra a violência expressam as possibilidades de uma governamentalidade, fundada na sociedade civil e na construção social da cidadania, buscandose a reconstrução das relações de sociabilidade mediante outras bases da solidariedade social.

Entre os agentes da transformação, podemos identificar as instituições da sociedade civil que promoveram tais lutas: a campanha de Hélio Bicudo contra os "grupos de extermínio" em São Paulo, nos anos 70; a campanha pela Anistia, de 1975 a 1979; o grupo ecumênico, católico, luterano e judeu, do movimento "Tortura Nunca Mais", no início dos anos 80; a Campanha Nacional contra a Violência, levada adiante pela OAB; e a Campanha sobre a Violência contra a Criança, organizada pela Confederação Nacional dos Bispos do Brasil - CNBB, Igreja Evangélica de Confissão Luterana do Brasil - IECLB e Comissão Pastoral da Terra - CPT.

Nos anos 90, assistimos a sucessivas campanhas contra a violência no campo, protagonizadas pela Comissão Pastoral da Terra, da CNBB, Confederação dos Trabalhadores na Agricultura - Contag e Instituto Brasileiro de Análise Sociais e Econômicas - Ibase, desde 1985; as Comissões de Direitos Humanos; as ONG, como o Movimento Viva Rio; as campanhas contra a violência à mulher; os movimentos de homossexuais denunciando a violência contra gays, lésbicas e travestis; as lutas do movimento negro, e tantas outras.

Também as campanhas contra a violência nos presídios, levadas adiante pela Comissão de Justiça e Paz Teotônio Vilela, da Arquidiocese de São Paulo; a mobilização pela desmilitarização das polícias militares esta- 
duais, capitaneada por Hélio Bicudo e pelo Núcleo de Estudos da Violência da USP, dirigido por Paulo Sérgio Pinheiro; a Comissão de Direitos Humanos da Câmara de Deputados, as Comissões de Direitos Humanos da Assembléia Legislativa do Rio Grande do Sul (Relatório Azul, 1994-2002); e a Campanha pela Paz nas Escolas, capitaneada pela Unesco.

\section{POSSIBILIDADES DE UM CONTROLE SOCIAL DEMOCRÁTICO}

Neste nascente século XXI, multiplicam-se os projetos para prevenir as violências e reduzir a criminalidade violenta, na perspectiva de novas alternativas de políticas públicas de segurança que possam garantir o direito de segurança dos cidadãos e cidadãs nas sociedades do século XXI. São efeitos múltiplos da mundialização da questão dos direitos humanos, desde a II Conferência Internacional de Direitos Humanos, reunida em Viena, em 1995.

Estamos, desde 2001, em um período de proposições para "um outro mundo possível", como aconteceu durante o Fórum Social Mundial de Porto Alegre, nos anos de 2001, 2002 e 2003. Entretanto, se muito se discutiu sobre a violência, em particular a violência doméstica e a violência contra os jovens, o debate sobre a questão da segurança foi escasso, e sobre a questão da reforma das polícias foi nulo.

Assistimos a uma virtual impossibilidade do ofício de policial, seja pelas dificuldades em garantir a ordem pública, por ela estar internacionalizada e privatizada, seja pelas limitações em contribuir à construção do consenso, pois as bases da comunidade não mais existem em sociedades complexas e com o mundo do trabalho desestruturado. A análise de várias situações reais pode levar a perceber a vigência, na sociedade brasileira, de uma representação social baseada em tecnologias de poder repressivas, mas também cabe salientar a emergência de ações coletivas e de trabalhos institucionais enquanto expressões de um movimento contra a violência.

Tal movimento de reforma do trabalho policial tem sido, por um lado, marcado por uma colaboração entre universidades e escolas de Polícia, em vários estados brasileiros, nos últimos anos, que tem sido franca e profícua, indicando um movimento de transformação de currículos, de conteúdos e de concepção do ofício de policial (em Minas Gerais, a UFMG e a Fundação João Pinheiro; no Rio Grande do Sul, a Universidade Federal do Rio Grande do Sul, desde 1992; no Rio de Janeiro, a UERJ e a
Universidade Federal Fluminense; em São Paulo, a USP; na Bahia, a UFBA; em Pernambuco, a UFPE; no Pará, a Universidade Federal do Pará, no Ceará, a Universidade Federal do Ceará).

Na mesma perspectiva, estão as experiências e as discussões acerca do modelo da polícia comunitária, ou da polícia de proximidade, mediante a análise das experiências no Canadá, na França, na Espanha, nos Estados Unidos e na Inglaterra, assim como em São Paulo, no Rio de Janeiro, na Bahia, no Amapá, no Espírito Santo e no Rio Grande do Sul (Mesquita Neto, 1998; Muniz, 1997). Também está em curso, no Brasil, uma discussão sobre a reforma das polícias estaduais, tendo sido lançado, em dezembro de 1999, um projeto de emenda constitucional que propõe um "novo modelo de polícia no Brasil", com os seguintes itens: unificação das polícias civis e militares em cada estado; extinção dos tribunais militares estaduais; eliminação do inquérito policial; e controle externo das polícias por ouvidorias.

Desta forma, para responder a tais processos sociais planetários, impõe-se propor uma diversificação nas alternativas de desenvolvimento para as sociedades contemporâneas, tanto no centro como na periferia do sistema global. Contra essa sociedade normalizadora e programada, efeito de uma tecnologia de poder centrada na vida, e de um Estado orientado para o controle social penal emergem, aparecem, no jovem século XXI, forças sociais de resistência, novos movimentos sociais, a crítica aos processos sociais de construção da violência simbólica e das "representações sociais da insegurança" e as concepções de uma polícia cidadã orientada para a mediação de conflitos.

Seria, então, possível, pensar a construção de uma cidadania transnacional ou mundial, marcada pela criação institucional e pela difusão e comunicação de práticas sociais, jurídicas e simbólicas, inovadoras e globais, no âmbito da sociedade civil: "É no âmbito da sociedade civil mundial, vista como o novo palco da história, que os indivíduos e as coletividades, as classes e os grupos, os gêneros e as etnias, as línguas e as religiões adquirem outros e novos significados, envolvendo movimentos de integração e fragmentação, acomodação e contradição, reforma e revolução" (Ianni, 2003:129).

Por um lado, a reinvenção das formas de solidariedade; por outro, a redefinição do trabalho, em múltiplas relações sociais, tanto no espaço rural como no espaço urbano; enfim, a prevenção e erradicação das formas de violência social; e a construção de um outro tipo de trabalho policial. 
Estamos no limiar de um processo político no qual a questão da segurança retoma as origens da polis e da politéia, como conjunto das instituições necessárias ao funcionamento e à conservação da cidade, incluindo-se o direito coletivo da segurança dos cidadãos e cidadãs.

Em outras palavras, a emergência de uma noção de segurança cidadã, na perspectiva da mundialização, supõe a construção social de controle social democrático, mediante o qual tanto as instituições de socialização - a família, a escola, as associações locais, os meios de comunicação - quanto as organizações do controle social formal - as polícias, o sistema judiciário, as instituições prisionais - reconstruam o objetivo de uma governamentalidade preocupada com as práticas de si, emancipatórias, dos conjuntos de cidadãos e cidadãs em suas vidas cotidianas, em suas trajetórias sociais e em seus sonhos de sociedade. Tais possibilidades estão presentes nas lutas sociais mundiais pela construção de uma sociedade democrática, com novas modalidades de controle social orientadas pelo respeito à dignidade humana.

\section{REFERÊNCIAS BIBLIOGRÁFICAS}

ADORNO, S. A criminalidade urbana violenta: um recorte temático. $B I B$ - Revista Brasileira de Informação Bibliográfica em Ciências Sociais. Rio de Janeiro, Anpocs, n.35, p.3-242, 1993.

ARON, R. Les étapes de la pensée sociologique. Paris: Gallimard, 1967.

AZEVEDO, R.G. de. Informalização da Justiça e controle social. São Paulo: IBCCrim, 2000.

BAUMAN, Z. Comunidade: a busca por segurança no mundo atual. Rio de Janeiro: Jorge Zahar, 2003.

O mal-estar da pós-modernidade. Rio de Janeiro: Jorge Zahar, 1998.

BAYLEY, D.H. Police for the future. New York: Oxford University Press, 1996.

BOURDIEU, P. Les structures sociales de l'economie. Paris: Seuil, 2000 .

La domination masculine. Paris: Seuil, 1998. (ed. br.).

(Ed.). La misére du monde. Paris: Seuil, 1993. (Ed. brasileira: Vozes).

BRETAS, M.L. O crime na historiografia brasileira. BIB - Revista Brasileira de Informação Bibliográfica em Ciências Sociais, Rio de Janeiro, n.32, p. 49-61, 1991.

BRICEÑO-LEÓN, R. (Org.). Violência, sociedad y justicia em America Latina. Buenos Aires: Clacso, 2002

BRUMER, A.; TAVARES DOS SANTOS, J.V. Estudos agrários no Brasil: modernização, violência e lutas sociais (desenvolvimento e limites da Sociologia Rural no final do Século XX). In: PIÑEIRO, D. (Org.). 30 años (anos) de Sociología Rural en (na) América Latina. Montevideo, Uruguay: ALASRU/SBS - Sociedade Brasileira de Sociologia, p.33-695, 2000.
CALDEIRA, T. Cidade de muros. Crime, segregação e cidadania em São Paulo. São Paulo: Edusp; Paralelo 34, 2000.

CASTEL, R. As metamorfoses da questão social. Petrópolis: Vozes, 1998.

CPT. Comissão Pastoral da Terra. Conflitos no Campo - 1988-2001. Goiânia, 1989 a 2002.

DÍAZ, E. Pós-modernidad. Buenos Aires: Eudeba, 1989.

DURKHEIM, E. Emile Durkheim: Sociologia. São Paulo: Ática, 1978.

ELIAS, N. O processo civilizador - Formação do Estado e civilização. Rio de Janeiro: Jorge Zahar, 1993, v.II.

O processo civilizador - Uma história dos costumes. Rio de Janeiro: Jorge Zahar, 1990, v.I.

FOUCAULT, M. Dits et Ecrits. Paris: Gallimard, tomo IV, 1994.

GARLAND, D. The culture of control. Oxford: Oxford University Press, 2001.

Punishment and modern society. Oxford, Oxford University Press, 1990

GIDDENS, A. Para além da esquerda e da direita. São Paulo: Ed. da Unesp, 1966.

As conseqüencias da modernidade. São Paulo: Ed. da Unesp, 1991.

GREGORI, M.F. Cenas e queixas. São Paulo, 1992.

GROSSI-PORTO, M.S. Elementos para uma reflexão sobre violência no Brasil dos Anos 90. Educação e Sociedade, Campinas, Papirus, ano XV, n.48, p.326-337, 1994.

HARVEY, D. A condição pós-moderna. São Paulo: Loyola, 1993.

HESPANHA, P. Novas desigualdades, novas solidariedades e reforma do Estado. Revista Crítica de Ciências Sociais, Coimbra, CES, n. 54, p.69-78, jun. 1999.

HOBSBAWM, E. Novo século. São Paulo: Companhia das Letras, 2000. . A era dos extremos. Rio de Janeiro: Paz e Terra, 1994.

IANNI, O. Sociologia do futuro. In: BARREIRA, C. (Org.). A sociologia no tempo: memória, imaginação e utopia. São Paulo: Cortez, 2003, p.107-131.

. Sociedade global, história e transculturação. In:TAVARES DOS SANTOS, J.V. Violências em tempo de globalização. São Paulo: Hucitec, 1999, p. 43-65. ra, 1996.

A era do globalismo. Rio de Janeiro: Civilização Brasilei-

JAMESON, F. Pós-modernismo: a lógica cultural do capitalismo tardio. São Paulo: Ática, 1996.

KANT DE LIMA, R.; MISSE, M.; MIRANDA, A.P.M. Violência, criminalidade, segurança pública e justiça criminal no Brasil: uma bibliografia. $B I B$ - Revista Brasileira de Informação Bibliográfica em Ciências Sociais, Rio de Janeiro, n.50, p.45-123, 2. sem. 2000.

LARANGEIRA, S. As transformações do trabalho num mundo globalizado. Revista Sociologias, Porto Alegre, n.4, p.14-19, 2000.

MELOSSI, D. El estado del control social. México: Siglo XXI, 1992.

MESQUITA NETO, P. Policiamento comunitário: a experiência em São Paulo. São Paulo: Núcleo de Estudos da Violência, Universidade de São Paulo, 1998.

MUNIZ, J. et al. Resistências e dificuldades de um programa de policiamento comunitário. Tempo social, São Paulo, Depto. de Sociologia da USP, v.9, n.1, p.197-213, 1997.

OLIVEN, R. Violência e cultura no Brasil. Petrópolis: Vozes, 1982. 
PAIS, J.M. Ganchos, tachos e biscates. Porto: Ambar, 2001.

PAVARINI, M.; PEGORARO, J. El control social en el fin del siglo. Buenos Aires: UBA, 1995.

PEGORARO, J. Inseguridad y violencia en el marco del control social. In: TAVARES DOS SANTOS, J.V. (Org.). Violências no tempo da globalização. São Paulo: Hucitec, 1999.

PEREIRA, C. et al. (Orgs.). Linguagens da violência. Rio de Janeiro: Rocco, 2000.

PINHEIRO, P.S.; MENDEZ, J.E.; O’DONNELL, G. Democracia, violência e injustiça. São Paulo: Paz e Terra, 2000.

REINER, R. The politics of the police. 3. ed. Oxford: Oxford University Press, 2000.

REVISTA SOCIOLOGIAS, Porto Alegre, PPG-Sociologia da UFRGS, n.1, set. 1999. (Dossiê "Conflitualidades").

REVISTA SOCIOLOGIAS, Porto Alegre, PPG-Sociologia da UFRGS, n.8, set. 2002. (Dossiê "Violências, América Latina").

ROSANVALLON, P. La nouvelle question sociale. Paris: Seuil, 1995.

SACHS, I. Estratégias de transição para o século XXI: desenvolvimento e meio ambiente. São Paulo: Nobel/Fundap, 1993.

SAFFIOTI, H.I.B.; ALMEIDA, S.S. de. Violência de gênero: poder e impotência. Rio de Janeiro: Revinter, 1995.

SCHNAPPER, D. La Relation à l'autre: au coeur de la pensée sociologique. Paris: Gallimard, 1998.

SOARES, L.E. Meu casaco de general. São Paulo: Cia. das Letras, 2000.

SOUSA SANTOS, B. A crítica da razão indolente: contra o desperdício da experiência. São Paulo: Cortez, 2000.

. Pela mão de Alice: o social e o político na pós-modernidade. Porto: Afrontamento, 1994.

SPOSITO, M.P. Um breve balanço da pesquisa sobre violência escolar no Brasil. Revista Educação e Pesquisa, São Paulo, Fac. de Educação da USP, v.27, n.1, jan./jun. 2001.

TAVARES DOS SANTOS, J.V. A sociologia para o século XXI: análise, responsabilidade e imaginação. In: BARREIRA, C. (Org.). $A$ sociologia no tempo: memória, imaginação e utopia. São Paulo: Cortez, 2003, p.195-213.
The worldization of violence and injustice. Current Sociology. London, ISA - International Sociological Association / SAGE, v.50, n.1, p.123-134, Jan. 2002a.

Microfísica da violência, uma questão social mundial. Ciência e Cultura. Revista da SBPC, São Paulo, ano54, n.1, p. 22-24, jul. 2002b. (Núcleo temático: Violência).

Violências, América Latina: a disseminação de formas de violência e os estudos sobre conflitualidades. Revista Sociologias, Porto Alegre, PPG - Sociologia do IFCH - UFRGS, n.8, p.16-32, nov. 2002c. (Tema: Violências, América Latina).

O saber do crime, a noção de violência e a seletividade penal. Delito y sociedad. Buenos Aires, v.9, n.14, p.94-106, 2000.

. (Org.). Violências em tempo de globalização. São Paulo: Hucitec, 1999.

Crítica da Sociologia Rural e a construção de uma outra sociologia dos processos sociais agrários. Ciências Sociais Hoje, São Paulo: Anpocs/Vértice, p.13-51, 1991.

TAYLOR, I. Crime in context. Cambridge: Polity Press, 1999.

TAYLOR, I.; WALTON, P.; YOUNG, J. La nueva criminologia. Buenos Aires: Amorrortu, 1990.

WACQUANT, L. Las cárceles de la miseria. Buenos Aires: Manantial, 2000.

L'ascension de l'état pénal en Amérique. Actes de la Recherche en Sciences Sociales, Paris, n.124, p.7-26, septembre 1998.

YOUNG, J. The exclusive society. London: Sage, 1999.

ZALUAR, A. Violência e crime. In: MICELI, S. (Org.). O que ler na ciência social brasileira. São Paulo: Anpocs/Sumaré, 1999. p.13-107. Condomínio do diabo. Rio de Janeiro: UFRJ, 1994.

José Vicente Tavares dos Santos: Sociólogo, Professor do Departamento de Sociologia e do Programa de Pós-Graduação em Sociologia, Diretor do Instituto de Filosofia e Ciencias Humanas da UFRGS, Pesquisador do CNPq; Membro do Conselho Nacional da SBPC, VicePresidente da Associação Latino-Americana de Sociologia (jvicente@portoweb.com.br). 